Please do not remove this page

RMIT

UNIVERSITY

\title{
Assessing organisational factors in aircraft accidents using a hybrid Reason and AcciMap model
}

Debrincat, J; Bil, Cornelis; Clark, Graham

https://researchrepository.rmit.edu.au/esploro/outputs/9921858673901341/filesAndLinks?institution=61RMIT_INST\&index=null

Debrincat, J., Bil, C., \& Clark, G. (2012). Assessing organisational factors in aircraft accidents using a hybrid Reason and AcciMap model. Engineering Failure Analysis, Online, 1-9.

https://doi.org/10.1016/j.engfailanal.2012.06.003

Published Version: https://doi.org/10.1016/j.engfailanal.2012.06.003

Repository homepage: https://researchrepository.rmit.edu.au

(c) 2012 Elsevier Ltd. All rights reserved

Downloaded On 2023/04/26 23:54:24 +1000

Please do not remove this page 
Thank you for downloading this document from the RMIT Research Repository.

The RMIT Research Repository is an open access database showcasing the research outputs of RMIT University researchers.

RMIT Research Repository: http://researchbank.rmit.edu.au/

\section{Citation:}

Debrincat, J, Bil, C and Clark, G 2013, 'Assessing organisational factors in aircraft accidents using a hybrid Reason and AcciMap model', Engineering Failure Analysis, vol. 27, pp. 52-60.

See this record in the RMIT Research Repository at:

http://researchbank.rmit.edu.au/view/rmit:18136

Version: Accepted Manuscript

Copyright Statement: (c) 2012 Elsevier Ltd. All rights reserved

Link to Published Version:

http://dx.doi.org/10.1016/j.engfailanal.2012.06.003 


\title{
ASSESSING ORGANISATIONAL FACTORS IN AIRCRAFT ACCIDENTS USING A HYBRID REASON AND ACCIMAP MODEL
}

\author{
J ustin Debrincat Cees Bil Graham Clark \\ School of Aerospace, Mechanical and Manufacturing Engineering, \\ RMIT University, Bundoora, Australia
}

Keywords: Accident Prevention, Reliability, Maintainability.

\begin{abstract}
Despite the use of high safety standards in aircraft design and operations, accidents do occur. In a process of continuous improvement it is essential that we learn from each accident so we can take measures to prevent such accidents from happening in the future. It is often the case that an accident is the result of a sequence of, seemingly minor and often unrelated, events. The challenge is to identify the major causes, which can include deficiencies in organisational processes which may have been present well before the accident itself. This paper discusses tools which can be used to identify key organisational factors which contribute to aviation accidents. The research uses a thoroughly-investigated helicopter accident as a case study, to determine the extent to which analytical and visualisation tools can be used to assess maintenance organisational issues which contributed to the accident.
\end{abstract}

\section{Introduction}

High levels of technological development in aviation have made it particularly difficult to analyse aircraft accidents involving extensive structural damage. Even when engineering and technological issues are resolved, there are complex management systems which need to be analysed to ensure that we identify the factors which initiated the accident. Unfortunately, history shows that it is often easier to focus on technological causes rather than deficiencies at an organisational level. These deficiencies, such as in training and maintenance services, the work environment and the often complex cultural issues which can influence human behaviour, can be difficult to identify and analyse, particularly when the investigation reveals a myriad of causal factors. Nevertheless, the purpose of the investigation is to prevent recurrence of the accident, and it is essential to identify all of the key underlying causal factors. The benefits are obvious - providing a basis for improvement in efficiency and overall safety, and maintaining public confidence in aviation.

This paper includes a discussion of the tools available for identifying and visualising the organisational factors that contribute to aviation accidents. It uses a major helicopter accident as a case study to assess some of these tools, and to determine which tools would assist with achieving organisational improvement to prevent recurrence. Finally, it develops a hybrid approach which could be applied to audits of maintenance performance, by analysing the many small maintenance breakdown events which are rectified before an accident occurs.

2. Case Study

In April, 2005, during a humanitarian aid mission after a major earthquake, a Royal Australian Navy Sea King helicopter N16-100 call sign Shark 02 crashed on the island of 
Nias, Indonesia (Fig. 1). Nine personnel were fatally injured and two were seriously injured in the accident.

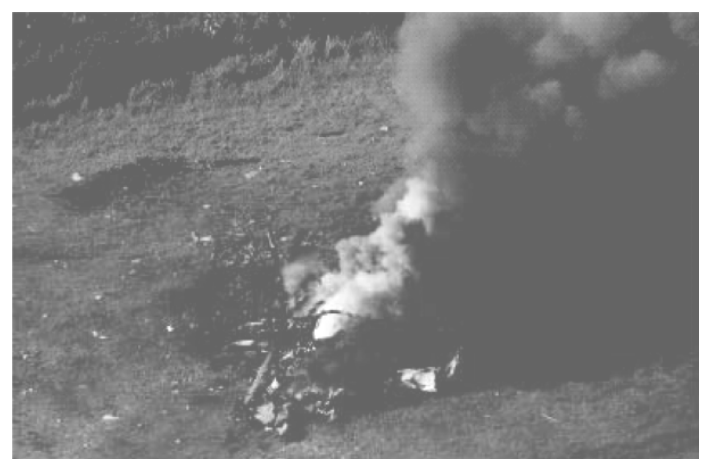

Fig. 1. RAN Sea King Accident Site, Nias [1]

The key event immediately before, and leading to, the accident was identified as a control linkage disconnect [1]. This was attributed to incomplete maintenance done some two months before the accident, but the Board of Inquiry (BOI) found that the root cause went far beyond a simple maintenance error [1]. Amongst the findings were many causal events including serious organisational as well as engineering deficiencies. The report also made approximately 250 recommendations with the aim of improving the overall management system for the fleet.

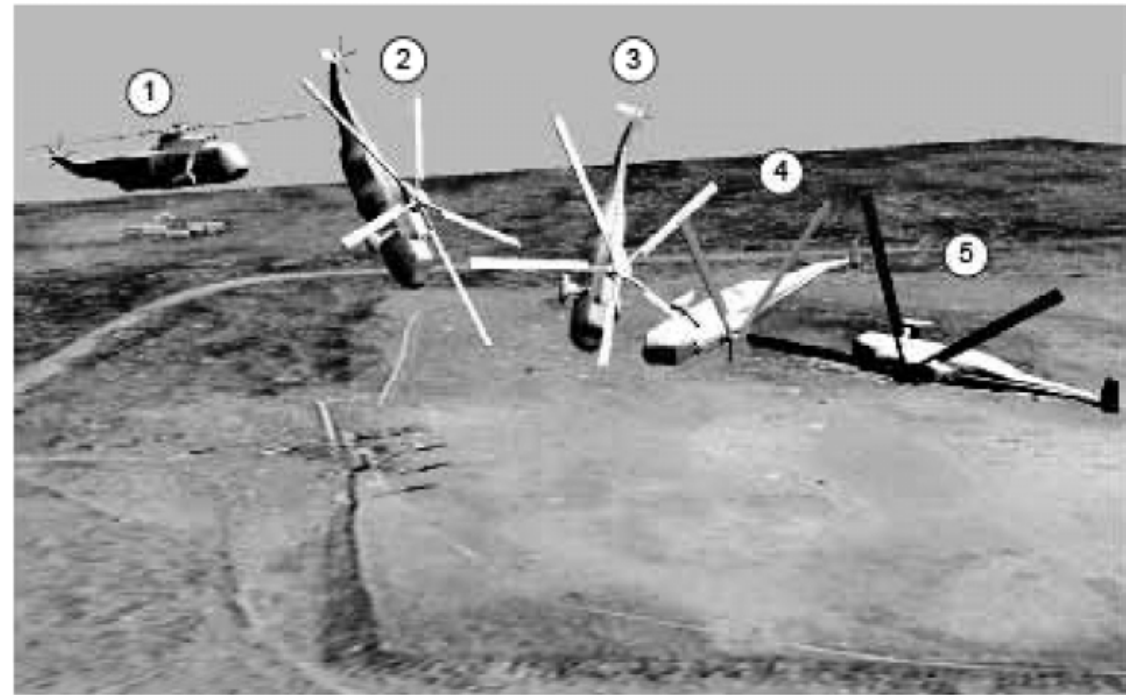

Fig. 2. Accident Sequence of Shark 02 [1]

The helicopter Shark 02 was on approach for landing, when witnesses observed it suddenly pitching down and the aircraft impacting the ground in a steep nose-down attitude. Figure 2 illustrates schematically the sequence of the accident. The mechanical cause was separation of a critical control system linkage, after a bolt slipped out of a joint. The bolt and nut should have been secured by a split pin, which was missing or ineffective.

The crash was reported extensively in the media, and while the primary cause of the accident was the failure of mechanical linkages, there were also contributory causes including:

- Deficiencies in maintenance practices in both the Sea King detachment and the Squadron; 
- Errors made by the Naval command and management systems;

- Deficiencies in the levels of support provided by Navy and the Defence organisation's safety, airworthiness, training and logistics management systems [2].

Furthermore, a report was written before the RAN Sea King accident, stating that the Squadron had insufficient staff and assets and was headed for 'an accident' [3]. The subsequent BOI report [1] highlighted a complex interaction of individual and systemic failings across the Australian Defence Organisation, and [4] that senior commanders and managers did not fully understand their responsibilities for airworthiness [4]. These issues, inter alia, give an indication of the nature of the causal factors identified in the investigation, and which were explored further in this research.

\section{Model}

\subsection{Background}

Modern models of accident causation take a systems approach, where accidents can be attributed to a combination of active operator-level errors [5]. This change from "single causal event" scenarios highlights the fact that there are some limitations associated with older models, i.e. too much focus on identifying causes as technological rather than considering the socio-economic climate. It is also widely recognised that there are both individual and organisational factors that contribute to maintenance performance, and these factors need to be identified to paint a credible, accurate and in-depth picture of the causes [6].

It was argued by Leveson [7] that the problem with a "human error" approach is that after an accident, it will be "easy to find someone involved in the dynamic flow of events that has violated a formal rule by following established practice rather than specified practice'. She argues that the way forward in accident investigations is to acknowledge human error as a 'deviation from a normal procedure', however that we should not stop there in the investigation; one must devise a more effective accident model that would require a shifting of focus from explaining human error to explaining organisational factors that shape this behaviour. This is a very important distinction. In support of this view, the need for a new model has also been suggested by Collett [8], stating that from 1972 to $1985,83 \%$ of all fatal aeromedical helicopter accidents were attributed to pilot error, while realistically, organisational and operational protocols and accepted practices may have created an environment where an accident was waiting to happen. Human error was just the catalyst of an accident sequence, laid down by a foundation of organisational deficiencies.

In summary, accident causation needs to be viewed as a complex process involving the entire socio-technical system, including legislators, government agencies, industry associations and insurance companies, company management, technical and engineering personnel, operations etc.

In the following sections, two models available for organizational analysis - the Reason model [9] and Rasmussen's AcciMap [10] will be described and their capabilities discussed. Both were applied to the case study, to allow a comparison, and to identify the extent the strengths and weaknesses which both might contribute if used in future accident investigations.

\subsection{Reason Model}

The J ames Reason Model, developed for analysing a wide range of organisational accidents, is widely used and accepted. Reason [11] developed his previously published $[9,12]$ causation analysis and created a user friendly model that can be adapted to almost any organisation. It bases itself on a diagrammatic representation of a system's defences, and highlights deficiencies in these defences that may lead to an accident [9]. 
The Reason Model, sometimes referred to as the Swiss Cheese Model, shown in Fig. 3, represents deficiencies in a system's defences by holes in slices looking like Swiss cheese. When the holes line up in consecutive slices, an accident trajectory becomes possible. Reason notes that these windows of opportunity, although possible, are rare because of the multiplicity of defences and the mobility of holes [9]. Furthermore, Reason adds that since no one can foresee all the possible scenarios of disaster, it is inevitable that some defensive weaknesses will be present from the beginning of a system's productive life.

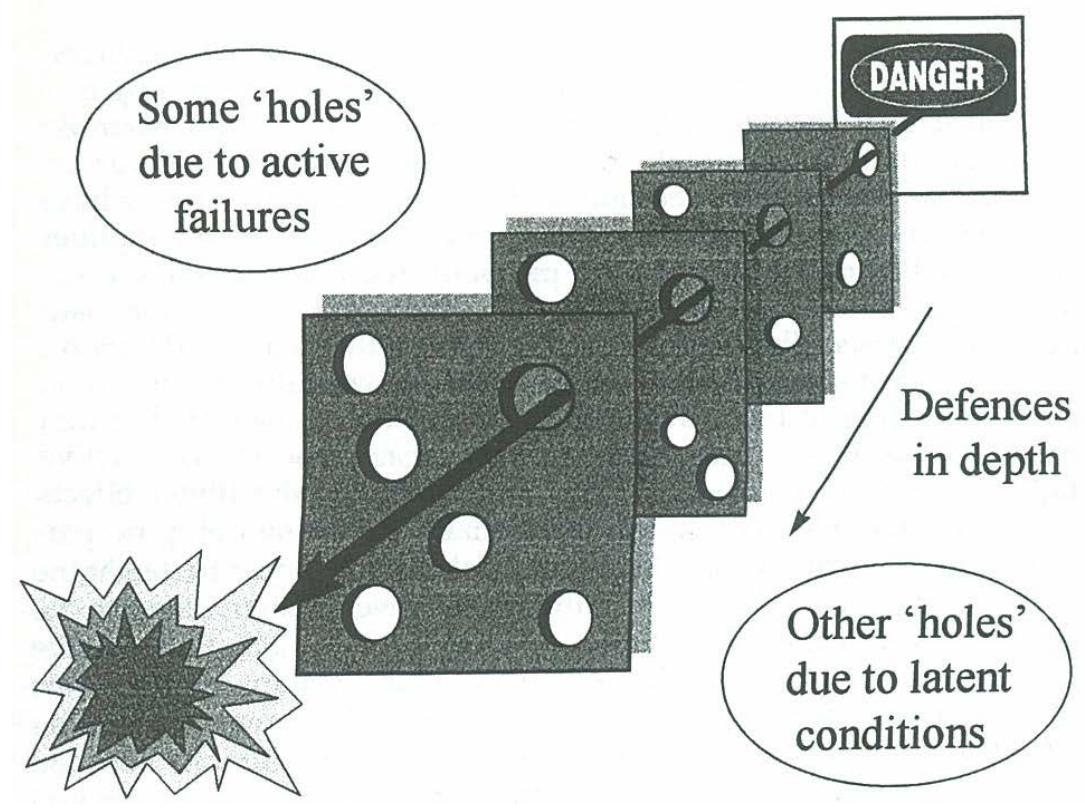

Fig. 3. J ames Reason's 'Swiss Cheese' Model [11]

The model explores two separate approaches to human error: the person approach and the system approach. Reason highlights that errors and violations committed at the sharp end of the system, for example by pilots, air traffic controllers, police officers, insurance brokers, financial traders, crews, control room operators and maintenance personnel, are related to immediate causes of accidents and if prevented, would most likely have broken the accident sequence. Until recently, this is where an accident investigation would stop, however Reason [11][12] explores the often neglected differentiation between active failures and latent conditions, and explores the notion of latent conditions, in which organisations that have experienced an accident may look beyond the sharp end to identify the causes to avoid a reoccurrence. These latent conditions include, for example, poor design, gaps in supervision, undetected manufacturing defects or maintenance failures, unworkable procedures, clumsy automation, shortfalls in training and less than adequate tools and equipment. 


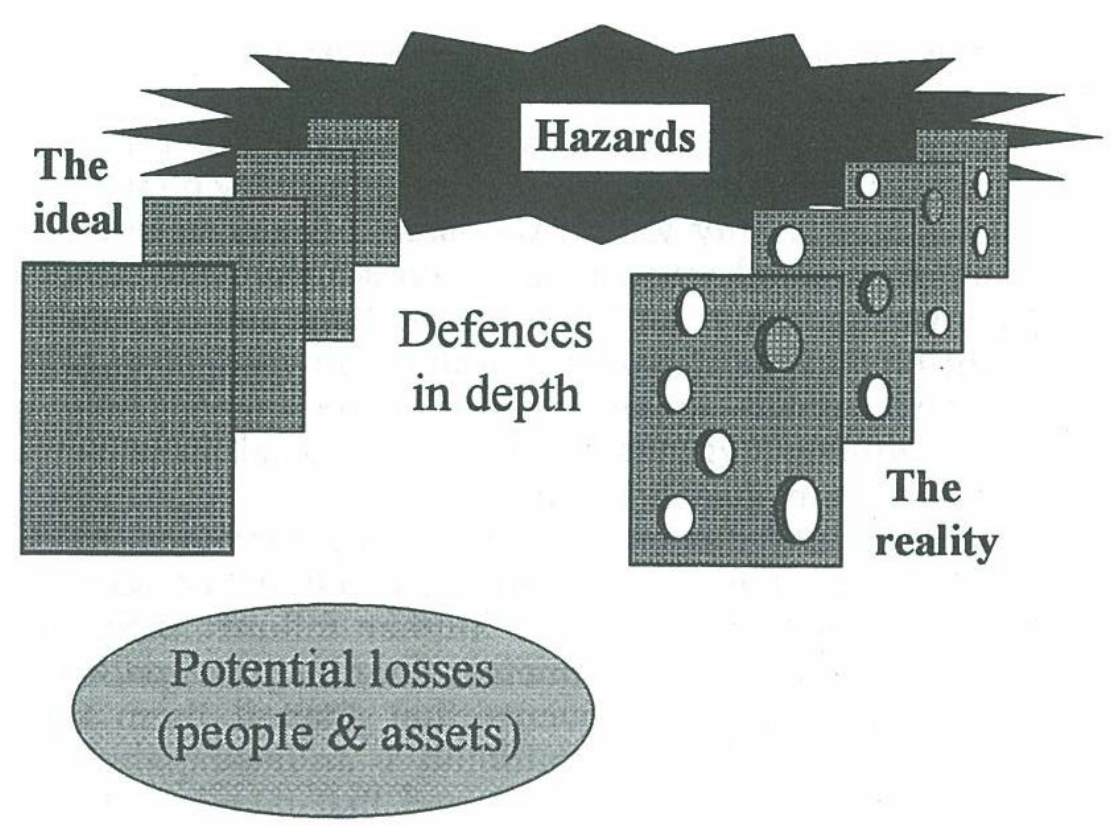

Fig. 4. Reason Model - The Ideal v The Reality [11]

In an ideal world, according to Reason [11], a system's defences would all be intact, allowing no penetration by possible accident trajectories, however, as illustrated in Fig. 4, in the real world each layer has weaknesses and gaps.

More recently, the dynamic state of organisational systems has been highlighted a time dimension has been introduced to the Reason model. In a review of the circumstances underpinning the crash of a RAF Nimrod aircraft, Haddon-Cave [13] observed that a culture of continual change in a regulatory system can have a major impact. He introduced this parameter to the Reason model by noting that the defence layers may also need to be modified to represent the successive changes in the system.

This approach highlights concern that a defence which was appropriate and effective at one moment in time might in subsequent years be rendered ineffective by continual change. In effect, moving the holes around opens up the potential for a complete accident trajectory. For the purposes of the present study, however, this dimension was not considered.

In identifying and exploring the defences of a system, we need to understand the various functions they serve and the way in which these functions are achieved. Defences are mechanisms put into place to counter inevitable mistakes from both human interaction and technology itself.

The functions of defence layers are:

- To create understanding and awareness of the local hazards;

- To give clear guidance on how to operate safely;

- To provide alarms and warnings when danger is imminent;

- To restore the system to a safe state in an off-normal situation;

- To interpose safety barriers between the hazards and the potential losses;

- To contain and eliminate the hazards should they escape this barrier;

- To provide the means of escape and rescue should hazard containment fail [11].

The ordering of the list above is not random and has significance in that the defences in depth concept highlights the proximity of some defences to the accident. This concept 
involves successive layers of protection, where each defence is guarding against a possible breakdown of the one before it, although the concept is weakened by the aforementioned dynamics issue, which allows opportunity for moving defences to reduce the reliability of the defences in depth concept.

\subsubsection{Reason Model Results}

Using the case study accident, a Reason Model was created for, using a number of key findings from the BOl report. The key defence mechanisms identified as being in place (Figure 5) were derived from; (i) the Military Regulatory System, (ii) Training, (iii) Management Monitoring, (iv) Standard Operating Procedures, (v) Communication and (vi) Helmet and Restraint.

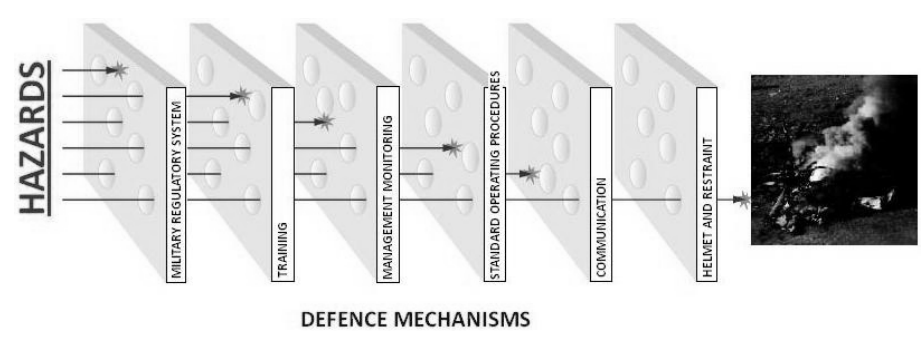

Figure 5: Key defence mechanisms in Reason Model of Sea King Accident

Although the model above illustrates and highlights the accident trajectory that caused the accident of Shark 02, it fails to provide the required depth to identify all of the causal factors. Preventing the accident from occurring or recurring requires this additional depth to identify specific improvements in the existing defences or the need for additional defences. An interesting observation made during this study, and a potential weakness, is that the Reason model is constrained to one accident trajectory, while it is conceivable that several trajectories might come together to contribute to the outcome.

In selecting the defences, the main themes from the BOI report were identified and summarised. The existing defence mechanisms put in place by the Squadron, and the Navy organisation as a whole were identified and categorised. Below is a breakdown of the defences, and more specifically their deficiencies or weaknesses that represent the holes in the Reason Swiss Cheese model. The higher level headings refer to the key defence mechanisms identified earlier in Figure 5.

\section{Military Regulatory Systems}

- Outdated FAR 29 Regulations

- 30 minute change-over procedures

- No legal obligation to comply with civil aviation safety standards

\section{Training systems}

- Failure to correctly certify and document maintenance procedures

- Staff not qualified to carry out certain maintenance operations

- No accompanying explanation as to why safety procedures exist

- Ineffective training days, lack of structure, planning and follow up testing and documentation

\section{Management Monitoring}

- Management did not ensure that staff carrying out maintenance activities were certified to do so 
- Officers who held specific positions were often not trained or experienced enough, a result of fast tracked promotion to fill gaps

- Inadequate supervision

4. Tested Standard Operating Procedures

- Pressure on increased fleet availability and a significant lack of resources forced practices away from established standard operating procedures

- Failure amongst junior maintenance engineers to understand the relevance and importance of standard operating procedures

\section{Communication systems}

- Breakdown of communication between watches

- Inadequate communication of audit findings and near misses

- Warnings from engineers largely went unheeded

\section{Personal Protective Equipment}

- Non-crashworthy seating

These defences were used as the basis for the reason model for the Sea King accident and they effectively identify the key aspects of the management system in place at the time.

\subsection{Rasmussen AcciMap}

The AcciMap was developed by Rasmussen [10]. It is a multi-layered causal diagram that arranges the various causes of an accident in terms of their causal remoteness from the accident. The Defence Science and Technology Organisation [14], who have used this approach, noted that the feature that distinguishes this method from that of an ordinary accident causation model is that it identifies causal factors from all parts of the system in which the accident occurred, ranging from the physical accident sequence of events and activities of the individuals involved, right up to the governmental, regulatory and social influences. 


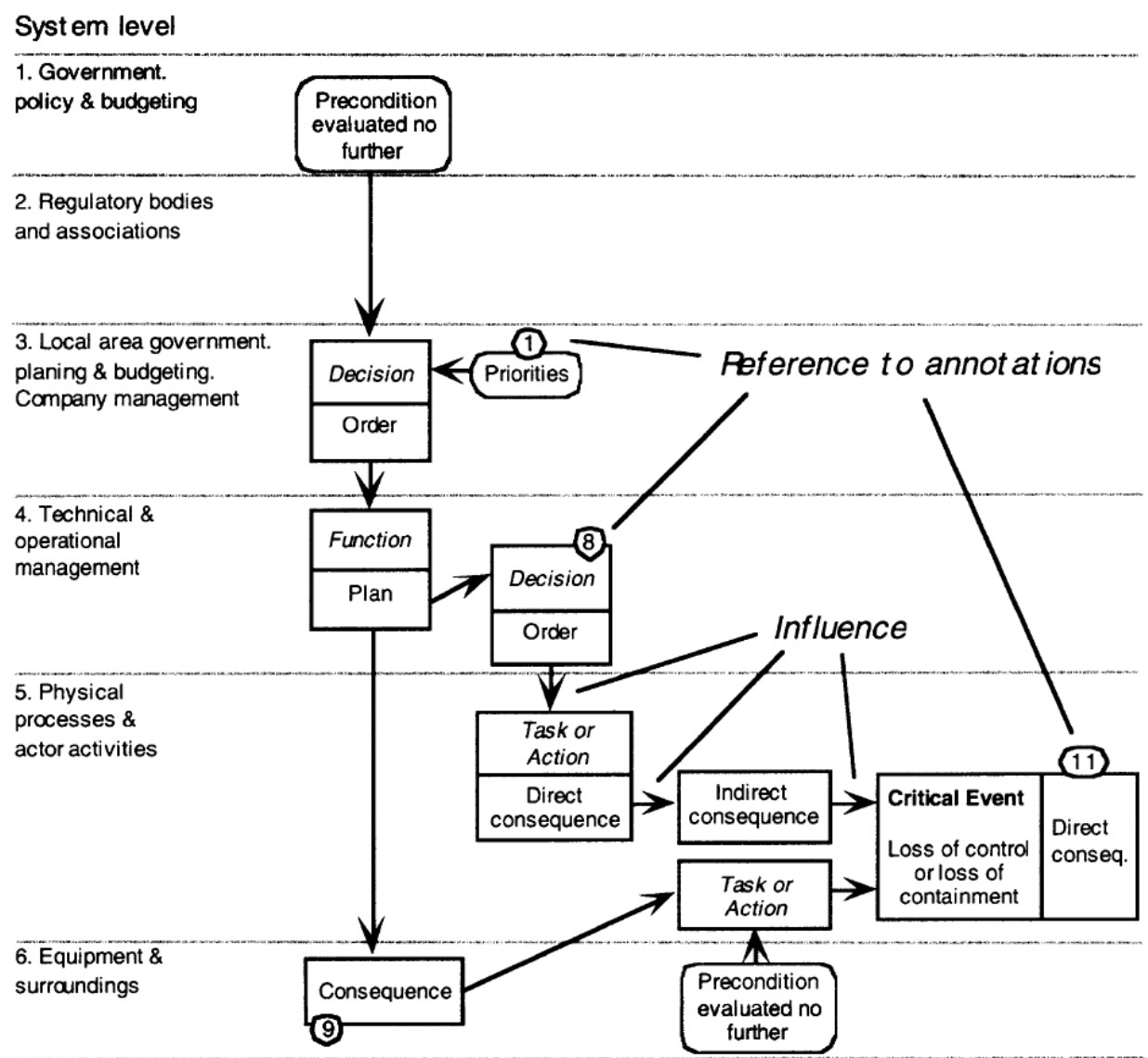

Figure 6: Potential Structure and Standardised Symbols of an AcciMap [10]

Figure 6 highlights the skeletal structure of the AcciMap, where levels of proximity are arranged vertically. The further down the chain of events, the closer to the accident sequence and final lines of defences. According to Svendung and Rasmussen [15] the focus of this analysis is the control of the hazardous process at the bottom of the sociotechnical system, therefore a vertical analysis covering all levels of influence is necessary as opposed to a horizontal, somewhat restricted approach.

AcciMap arranges these causal factors in a coherent, one page diagram that highlights the interrelationships between them, thereby highlighting the problem areas within the organisation that need to be addressed in order to prevent a similar chain of events occurring [14]. With this method, a broad situational view of the organisational and systemic inadequacies that contributed to the accident can be gained from essentially one concise, interlinking and user friendly map. To further increase clarity, any ambiguity of AcciMap and the nodes and arrows can be resolved through a textual argument.

The AcciMap approach has been applied to a number of case studies, all but one without aviation significance. It was used to highlight causal factors of a major (Esso Australia) gas plant explosion [16], and the results of that analysis were used to guide the development of an AcciMap for the present case study.

As discussed above, many past accident investigations have stopped once attribution of blame has been achieved, and there is still enormous public pressure to attribute blame to individuals or organisations. In selecting potential nodes (issues/ causes) for the RAN Sea King accident, it was necessary to go beyond such arbitrary barriers of causation analysis, to identify not only the matter of the missing split pin, and that this was due to an error involving a shift changeover and inadequate supervision, but why personnel were not adequately supervised and why this simple 
error in communication contributed to the event. Some of the challenges in building the model included:

- Developing a process to identify key causal factors from a large and detailed data set - in this case, the BOl Report. A key issue is that while the Reason model can be built around pre-identified defence systems, the AcciMap structure does not benefit from an initially defined structure, and may require substantial tailoring;

- Construction and layout of the AcciMap, especially interlinking and crossovers;

- Selecting nodes for inclusion in the model.

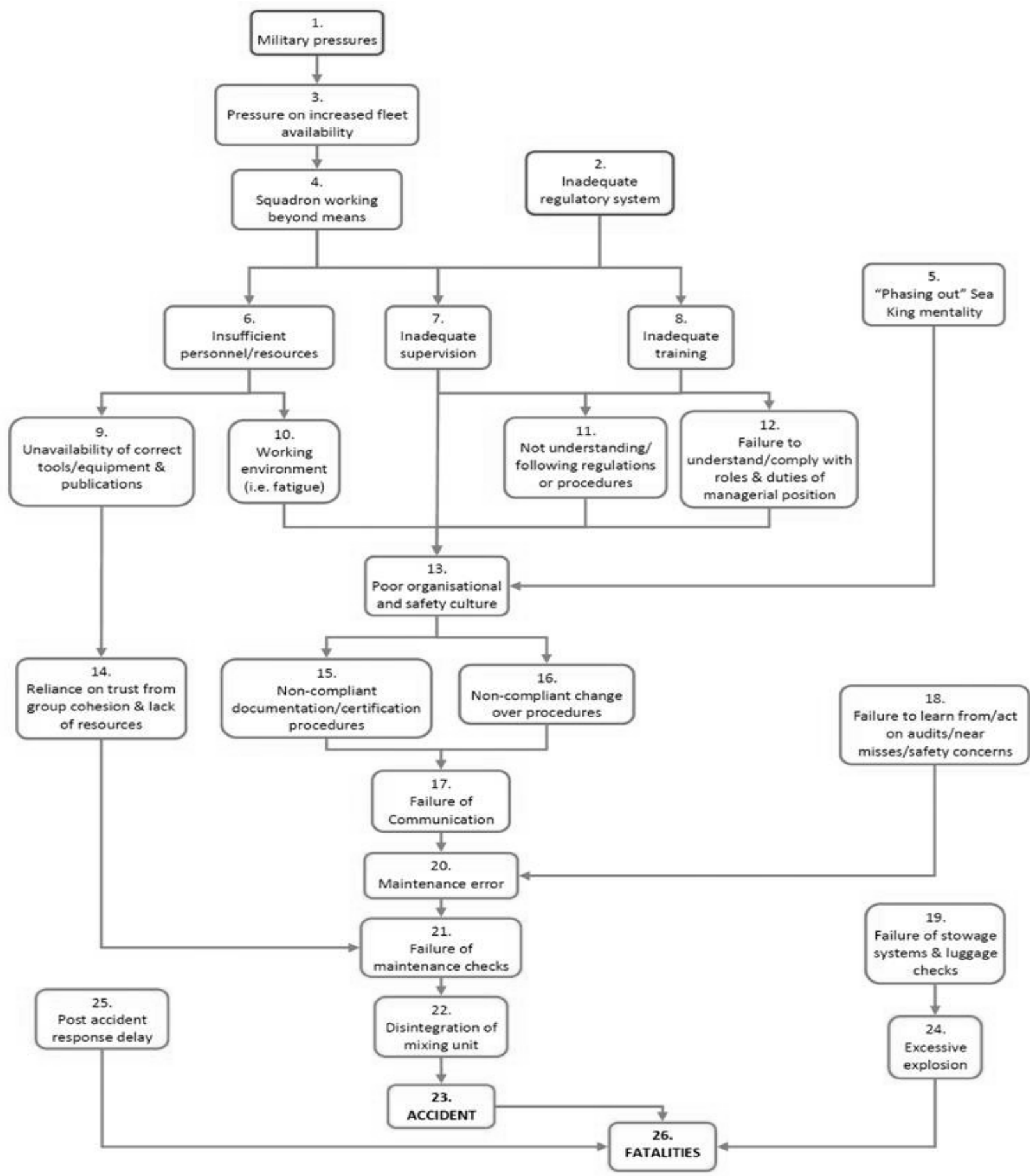

Figure 7: AcciMap developed for Sea King accident 


\subsubsection{AcciMap Results}

The AcciMap developed, and shown in Figure 7, explores the factors that interlinked to cause the fatal accident of Shark 02 . The causal remoteness increases as we move up the vertical axis from the accident. The red boxes indicate societal and governmental forces, the blue boxes the organisational deficiencies and the orange boxes, the physical accident sequence.

\section{Discussion}

One limitation of a study of this kind is that its structure is based on the use of just one source, the BOl report. However, that source is a well-founded, detailed, elaborate and non-subjective report that aimed to explore all causal factors contributing to the accident. For these reasons, this specific case study, due to the depth and transparency of the investigation, was believed to be suitable for trialling the AcciMap method paralleled with the Reason Model.

\subsection{Comparison of models}

Throughout the analysis, a comparison was made between the AcciMap and the Reason models. The two methods provide very different outputs and each may have value for different purposes. Notable features observed include:

- The Reason Model is constrained to one accident trajectory. In contrast, the AcciMap provides a networked analysis, with multiple nodal streams, and therefore is capable of offering a better "big-picture" view of the overall accident causal issues than does a linear sequence model;

- Since the Reason model focuses specifically on defences, it provides an excellent base for identifying and rectifying weaknesses in existing defensive measures;

- AcciMap offers the opportunity to identify, highlight, and hence modify or improve, a somewhat wider range of issues which contributed to the accident.

- The identification of AcciMap nodes is to some extent subjective, and it is not clear how the specifics of the results may be influenced by personal experience and understanding. Perhaps a more structured approach, based on developing a range of standard options for nodes, would be of value by providing a more robust approach to AcciMap generation. Ideally, an effective process will be sufficiently robust as to lead to identification of an essential causal chain and factors.

\subsection{Potential for combined application}

This study suggested that there could be benefit in using both models in parallel, to take advantage of the principal strengths of each. More specifically, the strength of AcciMap is that it provides a broad and comprehensive picture of the important issue-the nodes-which are involved in the accident. The principal strength of the Reason model is its focus on defences, and hence on potential improvements to the system. Use of the two models in a sequence where the key nodes identified in AcciMap could then be explored individually using a Reason approach, might provide a more robust outcome than using either model alone.

Figure 8 illustrates this concept by analysing, as an example, Node 12 in the Sea King AcciMap, shown in Figure 7. The four key defences for this particular node are Training, Management Monitoring, Standard Operating Procedures and Communication, 
and clearly this list provides a guide as to where attention should be focussed to improve safety and minimise the risk of recurrent accidents.

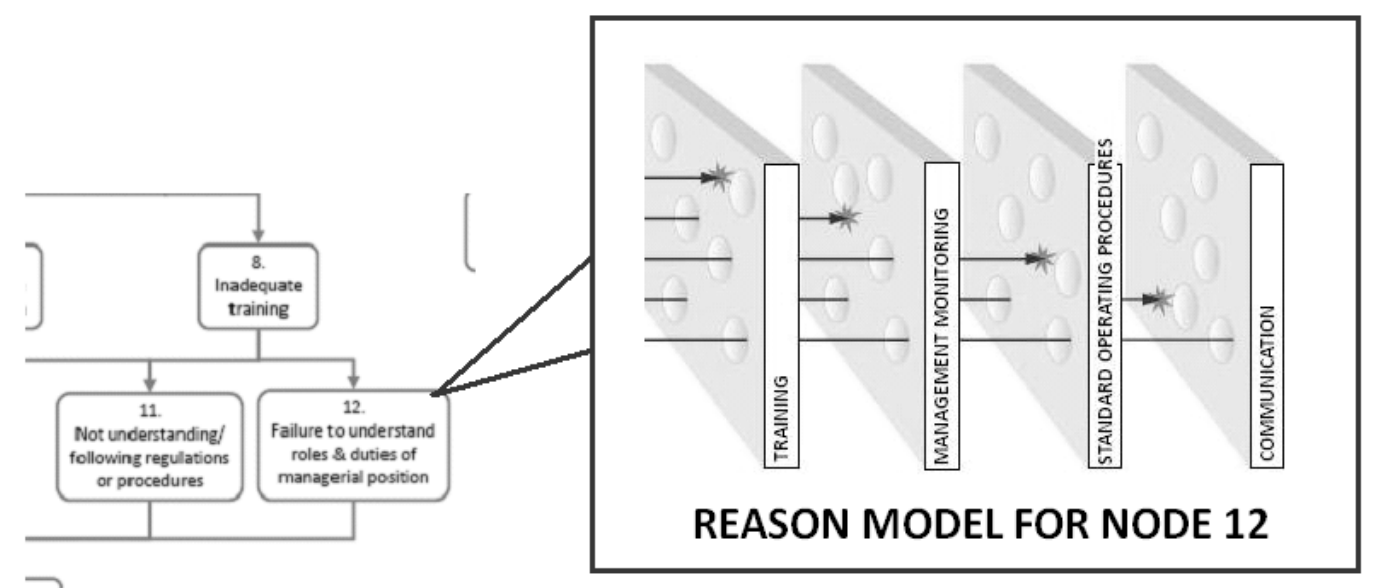

Figure 8: Hybrid AcciMap and Reason Model

A means of overcoming the limitations of performing the analysis at high level, is to explore the potential for use of the models recursively, i.e. can we re-apply the analysis to specific nodes of interest in AcciMap to access finer detail in the organisational structure? In the Reason Model, subdivision of defences seems relatively simple.

A major conclusion from this work is that since the focus of both models is to identify potential weaknesses in a system, there would be enormous benefit if the analyses could be conducted BEFORE an accident occurs. So how could we apply these models pro-actively? A key observation in the Sea King accident was that there had been a high number of maintenance breakdowns i.e. events which were noted before the accident, and which were intercepted before they could lead to an accident. This suggests that these maintenance breakdowns could be regarded as unfulfilled accidents, and application of the AcciMap and Reason models to these maintenance breakdowns would allow the organisation to improve its performance and safety levels.

What form would such a pro-active preventative analysis tool take? To be effective, it would need to be user-friendly and rapid, and capable of interrogating an organisation's existing records, something that should be feasible in a well-controlled environment such as the aviation industry. Such use of the analysis models, as a preventative measure, will be explored in further research. One issue is the need to better define a process for identification of key nodes in the AcciMap, not to produce different outcomes and results, but to reduce the amount of time and effort an organisation would need to put into the construction and maintenance of a preventative analytical tool.

\section{Conclusions}

This study has applied two organisational analysis tools to the case study of a major helicopter accident. The results of the processes led to several key conclusions:

- The models have different strengths - the AcciMap approach provides a better "bigpicture" view of the accident, with multiple causal streams. In contrast, the Reason model provides a more focused view of the system's defences and how they were breached to arrive at the accident;

- The identification of nodes in the AcciMap invites some subjectivity, and it is not clear to what extent, if any, this might affect the results; 
- The study identified some interesting potential applications which would exploit the strengths of the two models:

o Firstly, there is potential for using the two models together in an analysis which will use the AcciMap to identify (potentially) multiple strands of causal factors, then using the Reason approach to identify defences within the key nodes which can be improved;

- Secondly, the models could be re-applied to individual nodes in the AcciMap, to acquire a higher-resolution view of that aspect of system performance;

o Thirdly, the use of the two models, together, as a pro-active safety tool is proposed. Such a tool could be applied to recorded "maintenance breakdowns" in a safety-critical organisation. In effect, these recorded breakdowns can be viewed as incomplete accidents, allowing an organisation to self-assess its effectiveness and safety levels, and put in place improved safety methods.

\section{References}

[1] Royal Australian Navy. (2007). Nias Island Sea King Accident - Board of Inquiry Report. Australian Capital Territory: Commonwealth of Australia.

[2] [Machin, C. P. (2007, J uly 2). Series of Errors in Sea King Crash. Retrieved March 18, 2009, from Royal Australian Navy: www. navy.gov.au/Series_of_errors_in_Sea_King_crash

[3] Banham, C. (2005, December 3). Australia's Navy rēport förē̄old Sea King accident. Retrieved May 24, 2009, from Aviation Human Factors Industry News: http:/ / www. system-

safety. com/ Aviation\%20HF\%News/ Issue\%201\%20Volume\%204. htm

[4] Kerr, J. (2007). Inquiry attributes RAN Sea King crash to 'culture' of shortcuts. J ane's Defence Weekly , 1-2, 4 J uly 2007)

[5] Peters, G. A., \& Peters, B. J. (2006). Human Error - Causes and Control. Florida: Taylor and Francis.

[6] Fogarty, G. \& \& Saunders, R. (n.d.). Developing a Model to Predict Aircraft Maintenance Performance. Tenth International Symposium on Aviation Psychology, (p. 6). Ohio.

[7] Leveson, N. (2004). A new accident model for engineering systems. Safety Science, 237-270.

[8] Collett, H. M. (1986). The Safety Challenge. Hospital Aviation 5(3) , 5-8.

[9] Reason, J. (1995). A systems approach to organizational error. Ergonomics 38(8), 1708-1721.

[10] Rasmussen, J. (1997). Risk Management in a Dynamic Society: A Modelling Problem. Safety Science, 27(2/3), 183-213.

[11] Reason, J. (1997). Managing the Risks of Organizational Accidents. Ashgate Publishing Limited, England.

[12] Reason, J . (1990). Human Error. Cambridge University Press, Cambridge, United Kingdom.

[13] Haddon-Cave, C. (2009). An independent review into the broader issues surrounding the loss of the RAF Nimrod MR2 Aircraft XV230 in Afghanistan in 2006. London: The House of Commons.

[14] Defence Science and Technology Organisation. (2005, February 21). Retrieved March 6, 2009, from AcciMap Analysis - Further Information: www. dsto. defence. gov. au/ research/ page/ 3273

[15] Svendung, I., \& Rasmussen, J. (2002). Graphic representation of accident scenarios: mapping system structure and the causation of accidents. Safety Science, 40, 20.

[16] Hopkins, A. (2000). An AcciMap of the Esso Australia Gas Plant Explosion. ACT: Australian National University. 